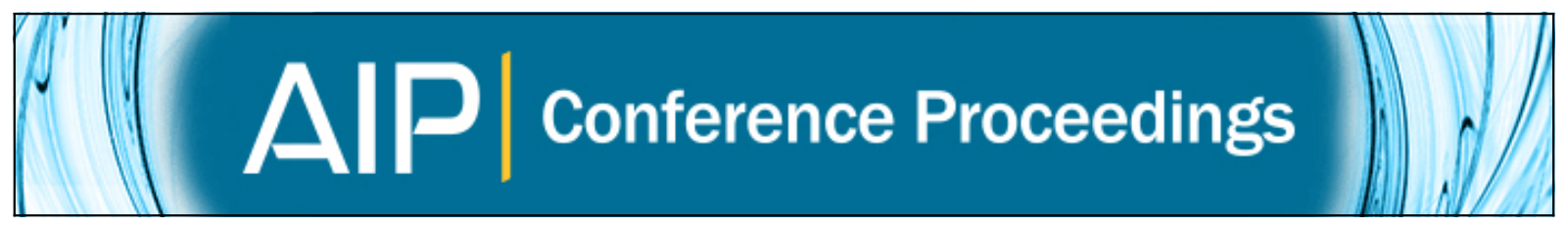

\title{
Preface of the "2nd Symposium on Modelling and Simulation in Computer Sciences
} and Engineering"

Francisco Miranda and Carlos Abreu

Citation: AIP Conference Proceedings 1738, 370001 (2016); doi: 10.1063/1.4952146

View online: http://dx.doi.org/10.1063/1.4952146

View Table of Contents: http://scitation.aip.org/content/aip/proceeding/aipcp/1738?ver=pdfcov

Published by the AIP Publishing

\section{Articles you may be interested in}

Preface of the "Symposium on High Performance Computing in Engineering and Environmental Sciences" AIP Conf. Proc. 1738, 360001 (2016); 10.1063/1.4952134

Preface of the "2nd Symposium on Computational Statistical Methods"

AIP Conf. Proc. 1702, 030001 (2015); 10.1063/1.4938767

Preface of the "Symposium on high performance computing in engineering and environmental sciences" AIP Conf. Proc. 1648, 830001 (2015); 10.1063/1.4913027

Preface of the "Symposium on modelling and simulation in computer sciences and engineering" AIP Conf. Proc. 1648, 710001 (2015); 10.1063/1.4912925

Preface of the "Symposium on computational issues on applications of differential equations in science and engineering"

AIP Conf. Proc. 1618, 823 (2014); 10.1063/1.4897859 


\title{
Preface of the "2nd Symposium on Modelling and Simulation in Computer Sciences and Engineering"
}

\author{
Francisco Miranda ${ }^{\mathrm{a}, \mathrm{b}}$ and Carlos Abreu $\mathrm{u}^{\mathrm{b}, \mathrm{c}}$ \\ ${ }^{a}$ CIDMA, Universidade de Aveiro, Aveiro, Portugal \\ ${ }^{b}$ Instituto Politécnico de Viana do Castelo, Viana do Castelo, Portugal \\ ${ }^{c}$ CMEMS-UMINHO, Universidade do Minho, Braga, Portugal
}

The 2nd Symposium on Modelling and Simulation in Computer Sciences and Engineering was held in the 13th International Conference of Numerical Analysis and Applied Mathematics (ICNAAM 2015), Rhodes, Greece, 23-29 September 2015.

Modelling and simulation, applied to computer science and engineering is an exciting research area that uses the computational power of modern information processing systems to improve our understanding about the real world. Computer simulations and graphical visualizations play a fundamental role developing mathematical models to examine problems that would be too expensive, too much dangerous, or even impossible to study by direct experimentation. Moreover, virtual prototyping, using modelling and simulating software, is a keystone process to bring down the overall cost of designing and developing novel products. Indeed, the rising number of organisations using these technologies has led to a dramatic increase in demand for better research and skilled professionals in this research area.

As in the first symposium, that was a great success in ICNAAM 2014, the aim of this 2nd symposium was to provide research regarding modelling and simulation techniques applied to the physical sciences and engineering, where the purpose of the section activities was to discuss theoretical studies and experimental results with interest in several topics like modelling in engineering sciences and technology, dynamical systems models and methods, computational methods in engineering, computer science modelling and simulation, computer networks modelling, optimization, simulation and control theory, stochastic optimization, numerical methods and simulation, systems modelling, computational mathematics, analysis of mathematical models, algorithms and data structures, software design, control and systems engineering. The titles presented were the following:

- Mathematical Modelling and Linear Stability Analysis of Laser Fusion Cutting

- An Integrated Approach for the Knowledge Discovery in Computer Simulation Models with a Multi-Dimensional Parameter Space

- Numerical Modeling of Cold Room's Hinged Door Opening and Closing Processes

- Oscillating Layer Thickness and Vortices Generated in Oscillation of Finite Plate

- Case Studies on Optimization Problems in MATLAB and COMSOL Multiphysics by Means of the LiveLink

- The Physical Model for Research of Behavior of Grouting Mixtures

- The Predictive Protective Control of the Heat Exchanger

- Mathematical Modeling and Optimization of Flow Structure in Stage of Francis Turbine of Micro Gas Turbine Power Plant

- Design of a Model Reference Adaptive Control (MRAC) System for the Pneumatic Valve of the Bottle Washer in Beverage Companies

- Evaluation and Optimization of the Performance of Frame Geometries for Lithium-Ion Battery Application by Computer Simulation

- Stabilization of Model-Based Networked Control Systems

- Adaptive and Context-Aware Detection and Classification of Potential QoS Degradation Events in Biomedical Wireless Sensor Networks

- Comparative Analysis of Numerical Models of Pipe Handling Equipment Used in Offshore Drilling Applications

- Economic Policy Optimization Based on Both One Stochastic Model and the Parametric Control Theory

International Conference of Numerical Analysis and Applied Mathematics 2015 (ICNAAM 2015)

AIP Conf. Proc. 1738, 370001-1-370001-2; doi: 10.1063/1.4952146

Published by AIP Publishing. 978-0-7354-1392-4/\$30.00 
- Getting Full Control of Canonical Correlation Analysis with the AutoBiplot.CCA Function

- Fitting Mathematical Models to Describe the Rheological Behaviour of Chocolate Pastes

\section{ACKNOWLEDGMENTS}

The organisers of the symposium thank to all the reviewers and the technical committee that assisted them to strengthen this important event. They also thank to the organisers of the International Conference of Numerical Analysis and Applied Mathematics for allowing to realize this symposium.

Technical Committee: Alexandre Madeira, António Abel Henriques, António Alberto Pinto, Bibudhendu Pati, Carla Barbosa, Chhabi Rani Panigrahi, Daniel Cesarini, Daniel Filipe Albuquerque, Daniel Miranda, Dinu Dragan, Duc Truong Pham, Dragan Ivetic, Fabricia Roos-Frantz, Giovanni Pau, Helena Sofia Rodrigues, Hugo Rodrigues, Huichu Liu, Humberto Varum, Isabel Gonçalves, James M. Raude, Jianye Hao, João F. Nunes, João Manuel R. S. Tavares, João Paulo Carmo, Jorge M. Delgado, Luca Cassano, Manuel Ricardo, Manuel Rui Alves, Marco Avvenuti, Marek Skowroński, Mario Collotta, Meera Viswavandya, Mehmet Aksit, Pandian Vasant, Paula Alexandra Rego, Paulo Caldas, Pedro Dinho da Silva, Pedro Dinis Gaspar, Pedro Moreira, Pedro Pinto, Pijush Samui, Rachita Misra, Rafael Z. Frantz, Raimundo M. Delgado, Ravi Raghunathan, Reza Gharoie Ahangar, Roohollah Kalatehjari, Rui Carneiro, Saad Aljebori, Salim Lahmiri, Sandro Sawicki, Sara Paiva, Sérgio Ivan Lopes, Sónia Dias, Tawanda Mushiri, Tiago Pedrosa, Torsten Hermanns, Toufik Al Khawli, Vana Jelicic, Yildirim Dalkiliç.

The symposium was supported by Portuguese funds through the CIDMA - Center for Research and Development in Mathematics and Applications, and the Portuguese Foundation for Science and Technology ("FCT Fundação para a Ciência e a Tecnologia"), within project UID/MAT/04106/2013, and the Centro de Estatística e Modelação of Polytechnic Institute of Viana do Castelo.

\section{Francisco Miranda}

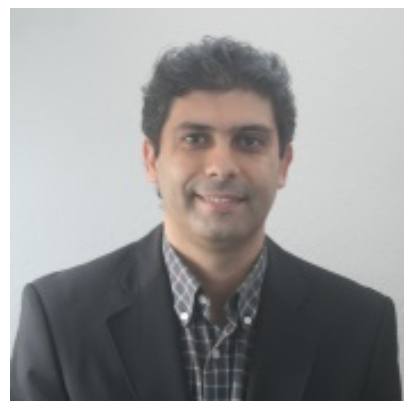

Francisco Miranda was born on April 1, 1975 in Viana do Castelo, Portugal. He graduated in Mathematics from University of Coimbra in 1999. Having done research on Control Theory he earned his MSc and PhD degrees in Applied Mathematics from University of Porto in 2003 and 2008, respectively. His research interests focus on stabilization and observability of control systems, optimal control, guidance control, numerical methods of stabilizer construction, time scales. Currently, he is Professor and Head of Mathematics Department at the Polytechnic Institute of Viana do Castelo, Portugal. He is also a researcher at Center for Research and Development in Mathematics and Applications, University of Aveiro, Portugal, and research collaborator at Centro de Estatística e Modelação of Polytechnic Institute of Viana do Castelo, Portugal.

\section{Carlos Abreu}

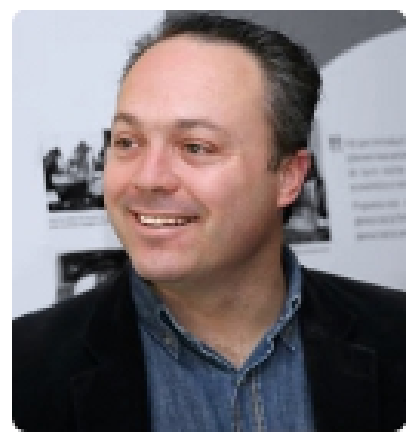

Carlos Abreu was born on September 8, 1976 in Esposende, Braga, Portugal. He graduated in Electronics and Telecommunications from University of Aveiro in 2005. Having done research on Instrumentation, Signal and Medical Image he earned his MSc degree in Biomedical Engineering in 2008. In 2014 he received his PhD in Biomedical Engineering from the University of Minho, Portugal. His research interests focus on: Wireless Sensors Networks for Medical Applications, Biomedical Instrumentation and Human Machine Interfaces for Disabled or Elderly People. Currently, he is working as Assistant Professor at the Polytechnic Institute of Viana do Castelo (IPVC). 